\title{
Risk factors for meningococcal disease in university halls of residence
}

\author{
S. J. NELSON ${ }^{1 *}$, A. CHARLETT ${ }^{2}$, H. J. ORR ${ }^{1}$, R. M. BARKER ${ }^{3}$, K. R. NEAL ${ }^{4}$, \\ C. TAYLOR ${ }^{5}$, P. N. MONK ${ }^{6}$, M. R. EVANS ${ }^{7}$ AND J. M. STUART ${ }^{1}$ \\ ${ }^{1}$ PHLS Communicable Disease Surveillance Centre (South West), Public Health Laboratory, Gloucestershire \\ Royal Hospital, Gloucester GL1 3NN \\ ${ }^{2}$ PHLS Statistics Unit, Colindale, London NW9 5EQ \\ ${ }^{3}$ Southampton and South West Hampshire Health Authority, Oakley Road, Southampton SO16 $4 G X$ \\ ${ }^{4}$ Public Health Medicine \& Epidemiology, University of Nottingham, Queen's Medical Centre, \\ Nottingham NG7 2UM \\ ${ }^{5}$ Student Welfare Office, University of Leicester, University Road, Leicester LE1 7RH \\ ${ }^{6}$ Department of Public Health, Leicestershire Health, Gwendolene Road, Leicester OE5 4QS \\ ${ }^{7}$ Bro Taf Health Authority, Temple of Peace \& Health, Cathays Park, Cardiff CF1 3NW
}

(Accepted 3 November 2000)

\section{SUMMARY}

A retrospective ecological study was undertaken to identify social and environmental factors associated with increased incidence of meningococcal disease in university halls of residence. A standardized questionnaire was sent to UK universities and colleges of higher education outside London, for distribution to halls containing at least 50 students. Incidence rate ratios of invasive meningococcal disease were obtained for a range of social and environmental variables. Multi-variable Poisson regression analysis identified 3 factors as having a strong association: a high proportion of first year undergraduate residents $(P=0 \cdot 0008)$, decreasing smokiness of the hall bar $(P<0.0001)$, and opening of hall bar before $1990(P=0.0001)$. The inverse relationship between disease incidence and smokiness of bars was an unexpected finding, and may be due to confounding factors. Universities should continue to promote awareness of meningococcal disease, encourage vaccination of first year students against serogroup $\mathrm{C}$ disease, and where appropriate, take measures to reduce overcrowding.

\section{INTRODUCTION}

Outbreaks of meningococcal disease in UK university students in recent years have drawn attention to the risk in this group [1]. The largest reported outbreaks have been in Cardiff and Southampton, involving a total of 13 cases in students, of whom 5 died [2-4]. A UK survey of meningococcal disease in young adults aged 18-21 years during the 4-year period 1994-7 found that the incidence was higher in university students than in other young people of the same age [5]. This excess incidence was noted particularly in

\footnotetext{
* Author for correspondence: Wiltshire Health Authority, Southgate House, Pans Lane, Devizes SN10 5EQ.
}

universities with a relatively high proportion of catered accommodation. In some universities certain halls of residence contributed a disproportionate number of cases. Seven out of a total of 12 clusters ( 3 or more cases in one university during a single term) occurred in a particular hall of residence [6]. University clusters, especially those associated with halls of residence, are believed to be due to close social contact among susceptible individuals [7]. However, it is not clear why particular halls of residence should have a greater risk of cases or clusters of disease than others.

A pilot study of social and environmental factors in halls of residence found an association between 
Table 1. Halls of residence and meningococcal disease: single variable analysis

\begin{tabular}{|c|c|c|c|c|c|}
\hline Variable & $\begin{array}{l}\text { Number } \\
\text { of halls }\end{array}$ & $\begin{array}{l}\text { Number } \\
\text { of cases }\end{array}$ & $\begin{array}{l}\text { Incidence per } \\
100000\end{array}$ & $95 \% \mathrm{CI}$ & $P$ value \\
\hline \multicolumn{6}{|l|}{ Year hall constructed } \\
\hline Before 1970 & 230 & 58 & $22 \cdot 1$ & $17 \cdot 1-28 \cdot 5$ & \\
\hline 1970-89 & 105 & 13 & $10 \cdot 7$ & $6 \cdot 2-18 \cdot 4$ & \\
\hline 1990 or after & 122 & 14 & $11 \cdot 0$ & $6.5-18 \cdot 5$ & $0 \cdot 007$ \\
\hline \multicolumn{6}{|l|}{ Distance from main campus } \\
\hline$<1$ mile & 331 & 44 & $12 \cdot 9$ & $9 \cdot 6-17 \cdot 3$ & \\
\hline $1-3$ miles & 148 & 44 & $22 \cdot 0$ & $16 \cdot 4-29 \cdot 5$ & $0 \cdot 01$ \\
\hline \multicolumn{6}{|l|}{ Hall has more than 500 residents } \\
\hline No & 428 & 59 & $16 \cdot 8$ & $13 \cdot 0-21 \cdot 6$ & \\
\hline Yes & 63 & 30 & $14 \cdot 7$ & $10 \cdot 3-21 \cdot 0$ & $0 \cdot 5$ \\
\hline \multicolumn{6}{|l|}{ Percentage of male residents } \\
\hline$<40 \%$ & 49 & 6 & $16 \cdot 1$ & $7 \cdot 2-35 \cdot 9$ & \\
\hline $40-60 \%$ & 293 & 57 & $16 \cdot 6$ & $12 \cdot 8-21 \cdot 5$ & \\
\hline$>60 \%$ & 61 & 2 & $3 \cdot 4$ & $1 \cdot 0-13 \cdot 8$ & 0.02 \\
\hline \multicolumn{6}{|l|}{ Type of accommodation } \\
\hline Single room on corridor & 275 & 37 & $13 \cdot 5$ & $9 \cdot 8-18 \cdot 6$ & \\
\hline Self contained flats & 140 & 22 & $13 \cdot 6$ & $8 \cdot 9-20 \cdot 6$ & \\
\hline Other & 43 & 4 & $6 \cdot 0$ & $2 \cdot 3-16 \cdot 0$ & $0 \cdot 2$ \\
\hline \multicolumn{6}{|l|}{ Type of hall } \\
\hline Single block & 167 & 10 & $9 \cdot 5$ & $5 \cdot 1-17 \cdot 6$ & \\
\hline Single block with satellite & 44 & 13 & $30 \cdot 5$ & $17 \cdot 7-52 \cdot 5$ & \\
\hline Multiple blocks & 225 & 58 & $17 \cdot 7$ & $13 \cdot 7-22 \cdot 9$ & \\
\hline Other & 19 & 0 & $0 \cdot 0$ & & 0.001 \\
\hline \multicolumn{6}{|l|}{ Percentage of first year students } \\
\hline$<50 \%$ & 78 & 6 & $5 \cdot 9$ & $2 \cdot 7-13 \cdot 2$ & \\
\hline $50-75 \%$ & 110 & 26 & $20 \cdot 0$ & $13 \cdot 6-29 \cdot 4$ & \\
\hline$>75 \%$ & 271 & 52 & $17 \cdot 7$ & $13 \cdot 5-23 \cdot 3$ & 0.006 \\
\hline \multicolumn{6}{|l|}{ Self catering } \\
\hline Some residents & 267 & 58 & $19 \cdot 7$ & $15 \cdot 2-25 \cdot 5$ & \\
\hline All residents & 221 & 31 & 11.9 & $8 \cdot 4-16 \cdot 9$ & $0 \cdot 02$ \\
\hline \multicolumn{6}{|l|}{ Single bedrooms } \\
\hline Some & 179 & 21 & $10 \cdot 1$ & $6 \cdot 6-15 \cdot 5$ & \\
\hline All & 308 & 67 & $19 \cdot 4$ & $15 \cdot 3-24 \cdot 7$ & 0.006 \\
\hline \multicolumn{6}{|l|}{ Catered residents per kitchen } \\
\hline Number of catered residents & 278 & 43 & $14 \cdot 1$ & $10 \cdot 5-19 \cdot 1$ & \\
\hline$<14$ & 76 & 10 & $11 \cdot 0$ & $5 \cdot 9-20 \cdot 4$ & \\
\hline 14 or more & 98 & 30 & $28 \cdot 7$ & $20 \cdot 1-41 \cdot 0$ & 0.005 \\
\hline \multicolumn{6}{|l|}{ Self catering residents per kitchen } \\
\hline Number of self catering residents & 211 & 42 & $20 \cdot 2$ & $14 \cdot 9-27 \cdot 4$ & \\
\hline$<7$ & 131 & 25 & $15 \cdot 6$ & $10 \cdot 5-23 \cdot 1$ & \\
\hline 7 or more & 135 & 20 & $12 \cdot 8$ & $8 \cdot 3-19 \cdot 9$ & $0 \cdot 2$ \\
\hline \multicolumn{6}{|l|}{ Smoking allowed in bedrooms } \\
\hline No & 49 & 27 & $37 \cdot 6$ & $25 \cdot 8-54 \cdot 8$ & \\
\hline Yes & 442 & 62 & $12 \cdot 8$ & $10 \cdot 0-16 \cdot 4$ & $<0.0001$ \\
\hline \multicolumn{6}{|l|}{ Smoking allowed in kitchen } \\
\hline No & 279 & 35 & $15 \cdot 3$ & $11 \cdot 0-21 \cdot 3$ & \\
\hline Yes & 212 & 54 & $16 \cdot 5$ & $12 \cdot 6-21 \cdot 5$ & $0 \cdot 7$ \\
\hline \multicolumn{6}{|l|}{ Smoking allowed in dining room } \\
\hline No dining room & 221 & 31 & 11.9 & $8 \cdot 4-16 \cdot 9$ & \\
\hline No & 234 & 57 & $21 \cdot 1$ & $16 \cdot 3-27 \cdot 4$ & \\
\hline Yes & 36 & 1 & $3 \cdot 8$ & $0 \cdot 5-27 \cdot 3$ & 0.005 \\
\hline \multicolumn{6}{|l|}{ Smoking allowed in common room } \\
\hline No room & 102 & 19 & $17 \cdot 2$ & $11 \cdot 0-27 \cdot 0$ & \\
\hline No & 178 & 45 & $19 \cdot 5$ & $14 \cdot 6-26 \cdot 1$ & \\
\hline Yes & 211 & 25 & $11 \cdot 6$ & $7 \cdot 9-17 \cdot 2$ & $0 \cdot 1$ \\
\hline
\end{tabular}


No

Yes

Variables related to the hall bar

Smoking allowed in bar

No bar

No

Yes

Year bar opened

No bar

Before 1970

1970-89

1990 or after

Bar volume

No bar

$<=425 \mathrm{~m}^{3}$

$>425 \mathrm{~m}^{3}$

Bar ventilation

No bar

Air conditioning

Windows

Recycled/Fans

Bar staffing

No bar

Residents

Paid bar staff

Both

Other

How noisy is bar?

No bar

Normal conversation

Need to speak up

Need to shout

Difficult to converse

How smoky is bar?

No bar

Not at all

Slightly

Moderately

Very

Annual turnover per resident

No bar

$<=£ 200$

$>£ 200$

Bar capacity

No bar

$<150$

$>=150$
352

139

33

56

$10 \cdot 4$

$23 \cdot 6$

$7 \cdot 4-14 \cdot 7$

$31 \cdot 5$

$0 \cdot 0$

$10 \cdot 4$

$10 \cdot 8$

$18 \cdot 0$

$24 \cdot 5$

$0 \cdot 0$

$10 \cdot 4$

$68 \cdot 5$

$44 \cdot 2$

$11 \cdot 0$

$6 \cdot 1$

$10 \cdot 4$

$20 \cdot 5$

$11 \cdot 4$

$10 \cdot 4$

$19 \cdot 6$

$20 \cdot 1$
$18 \cdot 1-30 \cdot 6$

$7 \cdot 4-14 \cdot 5$

$14 \cdot 8-51 \cdot 0$

$17 \cdot 5-31 \cdot 3$

$0 \cdot 7 *$

$7 \cdot 4-14 \cdot 6$

$21 \cdot 5-46 \cdot 3$

$16 \cdot 2-46 \cdot 1$

$3 \cdot 1-21 \cdot 7$

$7 \cdot 4-14 \cdot 6$

$22 \cdot 8-51 \cdot 7$

14.4-36.4

$7 \cdot 4-14 \cdot 6$

$9 \cdot 8-42 \cdot 9$

$15 \cdot 6-35 \cdot 3$

$18 \cdot 1-39 \cdot 0$

$0 \cdot 8 *$

$7 \cdot 4-14 \cdot 6$

16.7-41.1

5.9-20.3

19.9-50.0

0.0001

$0 \cdot 02 *$

$0 \cdot 2 *$

$-$

7.4-14.6

4.0-28.7

11.9-27.4

12.3-49.0

$0 \cdot 2 *$

$7 \cdot 4-14 \cdot 6$

$37 \cdot 9-123 \cdot 7$

28.5-68.6

$5 \cdot 7-21 \cdot 2$

2.0-18.8

$<0 \cdot 0001^{*}$

$7 \cdot 4-14 \cdot 6$

$12 \cdot 4-34 \cdot 1$

5.4-24.0

$0 \cdot 2 *$

$7 \cdot 4-14 \cdot 6$

$10 \cdot 5-36 \cdot 4$

$13 \cdot 7-29 \cdot 5$

$0 \cdot 02 *$

* Allowing for the bar effect.

incidence of meningococcal disease and halls of residence with bars. As the numbers were too small to be confident of this or other associations, this ecological study was extended to include universities and colleges of higher education involved in the previous UK incidence survey.

\section{METHODS}

We collected data on social and environmental characteristics of halls of residence. These data were linked with information previously collected as part of the UK incidence survey [5]. 


\section{Definitions}

Hall of residence. Single or multiple buildings designated by the university as a hall of residence for undergraduate students. Halls with fewer than 50 residents or with a majority of postgraduate students were excluded.

Case. Confirmed or probable case of meningococcal disease [8] in a student who was resident in a study hall. Cases were included if the onset occurred while the student was in residence or within the first 7 days after leaving residence.

Period of study. The 4 academic years 1994/5-1997/8.

Study population. Halls of residence of those higher education institutions in the United Kingdom in health authorities and boards that had provided data for the UK incidence survey. Universities and colleges in London were excluded because of difficulties in obtaining disease incidence data for London institutions [5].

\section{Data collection}

A standard letter and questionnaire were distributed to Vice Chancellors of universities and Principals of other colleges of higher education through the Committee of Vice Chancellors and Principals, and the Standing Committee of Principals. They were asked to arrange for completion of a separate questionnaire for each of their halls of residence that was eligible for inclusion in the study. Data were collected on 31 social and environmental variables including number and age of buildings, distance from main campus and students union, details of residents (numbers, study year, gender), catering arrangements, numbers of bedrooms and kitchens, smoking policy, and various variables relating to hall bars (age, capacity, size, ventilation, noise, smokiness, staffing, financial turnover). Numbers of cases of meningococcal disease by hall of residence had been ascertained previously [5].

\section{Analysis}

A Poisson regression analysis was used to study the association between the incidence of meningococcal disease and the social and environmental factors of interest. The number of cases of disease in a hall was modelled as the dependent variable and the social and environmental factors were the explanatory variables. The natural logarithm of the total number of personyears at risk was fitted as an offset. This model provided estimates of incidence rate ratios, together with $95 \%$ confidence intervals (CI), for each variable.

Each explanatory variable was first investigated individually for association with invasive meningococcal disease. Those showing an association with a $P$ value of $0 \cdot 1$ or less were included in a regression model. The significance of each variable included in the regression was assessed using the likelihood ratio test. Those with little evidence of effect were excluded from the model. All variables excluded by the single variable analysis were then tested against the final model to ensure they did not contribute toward the prediction. The final model was tested for all two-way interactions between the explanatory variables.

\section{RESULTS}

Of the 100 universities and colleges for which incidence data were available, $90(90 \%)$ responded. Questionnaires were completed for 501 halls of residence. Ten halls were excluded because of lack of data on numbers of residents. In the remaining 491 halls, which together contributed 556236 resident years, there were 89 cases of invasive meningococcal disease during the 4-year period of study. The overall incidence rate in these halls was 16.0 per 100000 resident years at risk (95\% CI 13.0-19.7).

The factors most strongly associated with the incidence of invasive disease (incidence rate ratio greater than 2 compared with baseline category) were: construction of hall before 1970, more than one accommodation block, $60 \%$ or less male residents, majority of students first year undergraduates, 14 or more residents per kitchen for non self-catering students, no smoking allowed in bedrooms or dining room, and halls with bars (Table 1). Among those halls with bars, the risk ratio was greater than 2 in halls with less smoky bars, older bars (opened before 1990), bars staffed by residents, and bars with a high background noise level (Table 1).

After excluding variables with little or no evidence of effect in the initial regression model, 3 factors were identified in the final model as having a strong association with the incidence of invasive meningo- 
Table 2. Halls of residence and meningococcal disease: Poisson regression model

\begin{tabular}{|c|c|c|c|c|}
\hline $\begin{array}{l}\text { Explanatory } \\
\text { variable }\end{array}$ & $\begin{array}{l}\text { Number } \\
\text { of halls }\end{array}$ & $\begin{array}{l}\text { Estimated incidence } \\
\text { rate ratio }\end{array}$ & $95 \% \mathrm{CI}$ & $P$ value \\
\hline \multicolumn{5}{|c|}{ Percentage of first years } \\
\hline$<50 \%$ & 78 & Reference & & \\
\hline $50-75 \%$ & 110 & $2 \cdot 95$ & $0 \cdot 84-10 \cdot 23$ & \\
\hline$>75 \%$ & 271 & $5 \cdot 43$ & $1 \cdot 67-17 \cdot 68$ & 0.0008 \\
\hline \multicolumn{5}{|l|}{ Year bar opened } \\
\hline No bar & 352 & Reference & & \\
\hline Before 1970 & 56 & $13 \cdot 90$ & $6 \cdot 56-29 \cdot 45$ & \\
\hline $1970-89$ & 53 & $14 \cdot 23$ & $4 \cdot 55-44 \cdot 51$ & \\
\hline 1990 or after & 27 & $1 \cdot 32$ & $0 \cdot 28-6 \cdot 28$ & $0 \cdot 0001$ \\
\hline \multicolumn{5}{|c|}{ How smoky is the bar? } \\
\hline No bar & 352 & & & \\
\hline Not at all & 7 & Reference & & \\
\hline Slightly & 29 & $0 \cdot 58$ & $0 \cdot 26-1 \cdot 31$ & \\
\hline Moderately & 58 & $0 \cdot 14$ & $0.05-0.38$ & \\
\hline Very & 24 & $0 \cdot 06$ & $0 \cdot 01-0 \cdot 29$ & $<0 \cdot 0001$ \\
\hline
\end{tabular}

Table 3. Halls of residence and meningococcal disease: other significant variables

\begin{tabular}{llll}
\hline \hline & $\begin{array}{l}\text { Estimated incidence } \\
\text { rate ratio }\end{array}$ & $95 \% \mathrm{CI}$ & $P$ value \\
\hline $\begin{array}{l}\text { Residents per kitchen for catered } \\
\text { students }\end{array}$ & & & \\
$\quad$ No catered residents & Reference & & \\
$\quad<14$ & 0.64 & $0.28-1.47$ & \\
$\quad 14$ or more & 1.71 & $0.89-3.29$ & 0.05 \\
Single bedrooms & & & \\
$\quad$ Some & Reference & & \\
$\quad$ All & 1.78 & $1.05-3.04$ & 0.03 \\
\hline \hline
\end{tabular}

coccal disease: proportion of first year undergraduate residents, smokiness of the hall bar, and date the bar was opened (Table 2).

Complete data on these three variables were available for a total of 419 halls. Sixty-nine cases occurred in these halls during the study period, giving an incidence of 15.3 per 100000 resident years at risk. This is close to the overall rate of 16 per 100000 , suggesting that halls excluded from the model because of missing data did not differ significantly with respect to the incidence of invasive meningococcal disease from those included in the model.

A higher proportion of first year undergraduate residents was associated with an increased incidence of invasive meningococcal disease. In halls with more than $75 \%$ first year residents the incidence rate ratio was about 5 times the rate in halls with less than $50 \%$.
Halls with a bar that first opened before 1990 had 14 times the incidence of cases compared with the rate in halls without a bar. In the 27 halls with bars that had opened since 1990 there was no significant difference in incidence compared with the rate in halls without bars. A strong inverse association was found between the smokiness of the hall bar and the incidence of cases. Halls with bars that were not at all smoky had rates about 17 (95\% CI: 3.4-100) times higher than bars that were very smoky. No evidence was found of interaction between these variables.

After allowing for the three strongly associated variables, halls with an average of 14 or more students sharing each kitchen for non self-catering residents, and halls with no shared bedrooms demonstrated a weaker but significant association with the incidence of cases (Table 3). 


\section{DISCUSSION}

Several social and environmental factors were associated with a higher incidence of meningococcal disease in student halls. While some can be explained by the known epidemiology of meningococcal infection, others are more difficult to interpret. A major difficulty in interpretation of ecological studies is that statistical associations between variables based on characteristics of study populations cannot necessarily be extrapolated to the individual level.

The increased incidence of cases in halls with a higher proportion of first year undergraduates is consistent with a greater overall susceptibility to invasive meningococcal disease in this group. Agespecific incidence in young adults peaks at around the age of 18 years [9]. First year students would thus be expected to have a higher incidence than older age groups. Furthermore, exposure to previously unencountered pathogenic strains of meningococci is likely to be higher among new students. Halls with a lower proportion of first years would be expected to have a more stable population, and thus lower levels of population mixing.

The higher incidence observed in halls with bars and with more residents per kitchen may be due to greater levels of social mixing, with susceptible individuals more likely to come into close contact with carriers of pathogenic strains. Overcrowding is a well established risk factor for meningococcal disease $[10,11]$. Similarly the lower incidence in halls with bars that opened in the last 10 years could be attributable to reduced levels of crowding and improved ventilation, although no association between disease incidence and bar ventilation was found in this study. This finding has not been adequately explained, but has potential implications for bar design.

The inverse relationship with smokiness of the bar was the strongest of the 3 predictors in the final model. This was an unexpected finding. Smoking is associated with meningococcal carriage $[12,13]$ and close contact with smokers is associated with an increased risk of disease $[8,14,15]$. A campus outbreak in the United States of America was associated with attendance at a smoky bar [16]. The information collected about smokiness was highly subjective but the dose response relationship was strong. Confounding due to variables not measured in the study is likely. For example, it is possible that the more smoky bars were avoided by non-smoking students or were less crowded. It did not prove possible to assess overcrowding and proximity of face-to-face contact in this survey.

The noise level within the bar was not a significant independent risk factor. However, risk was found to increase with increasing noise to the level where it was necessary to shout (adjusted incidence rate ratio 3.96 compared with bars where normal conversation was possible), and then to fall. This association may relate to the likelihood of droplet transmission, such that risk increases with rising speech volume and diminishing face-to-face distance until speech becomes impossible or 'mouth to ear' only.

Research into individual risk factors in teenagers will assist in the interpretation of the findings from our study. A case control study is currently in progress in England (J. Tully, personal communication). In the meantime universities and colleges of higher education could, where appropriate, take measures to reduce overcrowding in halls of residence. The recently introduced vaccination of first-year students against serogroup C disease should be supported. Awareness of meningococcal disease among university students and staff must be maintained, since the vaccination programme will not protect against the more common serogroup B strains.

\section{ACKNOWLEDGEMENTS}

We are most grateful to those at the universities and colleges who completed the questionnaires, and for the support of the Committee of Vice Chancellors and Principals and the Standing Committee of Principals in conducting this survey.

\section{REFERENCES}

1. CDSC. Managing meningococcal disease in higher education institutions. CDR 1998; 8: 219-22.

2. Gilmore A, Jones G, Barker M, Soltanpoor N, Stuart JM. Meningococcal disease at the University of Southampton: outbreak investigation. Epidemiol Infect 1999; 123: 185-92.

3. CDSC. Outbreak of meningococcal disease in students in Cardiff. CDR 1996; 6: 425.

4. CDSC. Clusters of meningococcal disease in university students. CDR 1997; 7: 393.

5. Neal KR, Nguyen-van-Tam J, Monk P, O'Brien SJ, Stuart J, Ramsay M. Invasive meningococcal disease among university undergraduates: association with universities providing relatively large amounts of catered accommodation. Epidemiol Infect 1999; 122: 351-7.

6. Neal KR, Nguyen-Van-Tam JS, Monk P, O'Brien SJ, Stuart J, Ramsay M. Predicting a second case of invasive meningococcal disease in the same term 
amongst university students. Abstracts of the Eleventh International Pathogenic Neisseria Conference. Paris: Eleventh International Pathogenic, Neisseria Conference, 1998: 98.

7. Neal KR, Nguyen-Van-Tam JS, Jeffrey N, et al. Changing carriage rate of Neisseria meningitidis among university students during the first week of term: cross sectional study. BMJ 2000; 320: 846-53.

8. Stuart JM, Monk PN, Lewis DA, Constantine C, Kaczmarski EB, Cartwright KAV. Management of clusters of meningococcal disease. CDR Rev 1997; 7 : R3-4.

9. Jones D. Epidemiology of meningococcal disease in Europe and the USA. In: Cartwright K, ed. Meningococcal disease. Chichester: Wiley, 1995: 147-57.

10. Stanwell-Smith RE, Stuart JM, Hughes AO, Robinson $\mathrm{P}$, Griffin MB, Cartwright K. Smoking, the environment and meningococcal disease: a case control study. Epidemiol Infect 1994; 112: 315-28.

11. Kaiser AB, Hennekens CH, Saslaw MS, Hayes PS, Bennett JV. Seroepidemiology and chemoprophylaxis of disease due to sulfonamide-resistant Neisseria meningitidis in a civilian population. J Infect Dis 1974; 130: $217-24$.

12. Stuart JM, Cartwright KAV, Robinson PM, Noah ND. Effect of smoking on meningococcal carriage. Lancet 1989; ii: 723-5.

13. Thomas JC, Bendana NS, Waterman SH, et al. Risk factors for carriage of meningococcus in the Los Angeles county men's jail system. Am J Epidemiol 1991; 133: 286-95.

14. Cookson ST, Corrales JL, Lotero JO, et al. Disco fever: epidemic meningococcal disease in North Eastern Argentina associated with disco patronage. J Infect Dis 1998; 178: 266-9.

15. Fischer M, Hedberg K, Cardosi P, et al. Tobacco smoke as a risk factor for meningococcal disease. Pediatr Infect Dis J 1997; 16: 979-83.

16. Imrey PB, Jackson LA, Ludwinski PH, et al. Outbreak of serogroup $\mathrm{C}$ meningococcal disease associated with campus bar patronage. Am J Epidemiol 1996; 143: 624-30. 